\title{
RELATION BETWEEN THE COOLING TIME AND FRICTION RESULTS IN BRAKING TESTS
}

\author{
P. D. Neis ${ }^{1,2}$, E. Schmidt ${ }^{1}$, G. L. P. G. Zanetti ${ }^{1}$, Y. Perez Delgado ${ }^{2}$, P. De Baets ${ }^{2}$ and N. \\ F. Ferreira ${ }^{1}$ \\ ${ }^{1}$ Federal University of Rio Grande do Sul, Brazil \\ ${ }^{2}$ Ghent University, Laboratory Soete, Belgium
}

\begin{abstract}
The current paper intends to evaluate the influence of the cooling time on friction results during braking performed on a laboratory-scale tribometer. At the same time, a possible correlation between the oxidation process and emissivity on the disk surface during cooling time is investigated. Sample and disk used in the tests are from a commercial available brake car. Procedure includes changes in the cooling times, where 4 different conditions are experienced: 18s, 90s, 600s and 24h. Friction curves reveal differences between the results obtained with $18 \mathrm{~s}, 90 \mathrm{~s}$ and $600 \mathrm{~s}$. Likewise, when a cooling time of $24 \mathrm{~h}$ is used, the first stop shows a considerable reduction in the coefficient of friction. It was not possible to find out the reason for this effect since relationship between friction and oxidation degree, verified by means of emissivity on the disc surface, could not be encountered.
\end{abstract}

Keywords: friction, braking, oxide layer, tribometer

INTRODUCTION

The great technological progress from the last decades has enabled the development of powerful vehicles which require more efficient brake systems at the same time. Nowadays, numerous studies related to friction materials of vehicles brake systems have been done in order to improve these systems. It is known that there are three main variables which influence the brake performance: sliding speed, contact pressure and temperature [1]. However, other variables also affect the behavior of the coefficient of friction: material constitution, surface roughness, environmental conditions, mechanical system, acceleration and deceleration [2].

In the current paper, different cooling times of the disk are used in the braking tests performed on a laboratory-scale tribometer in order to characterize the influence of this variable on the coefficient of friction. At the same time, ratio between changes in coefficient of friction and oxide layer, which is formed on the disk surface during the cooling period are analyzed. Oxide layer characterization is associated to the emissivity variation on the disk surface during the stops.

\section{EXPERIMENTAL APPARATUS}

The tests are performed on a laboratory-scale tribometer designed by the research group from Federal University of Rio Grande do Sul, Brazil. This machine is able to perform tests in conditions of temperature, pressure and velocity as those in real car brakes. Friction samples have a small size in order to allow versatility during the tests and reduce costs.

Regarding to the rotating system, the tribometer can operate in two modes:

1) Constant drag mode: rotating speed of the disk is kept constant over time during the stops.

2) Disk deceleration mode: rotating speed of the disk decreases at a pre-set rate as the braking proceeds, similar to the braking process in cars and test procedures performed on brake dynamometers.

Regarding to the load/actuator system, the tribometer can operate in two different modes:

1) Constant force mode: the normal force on the disk, which is done by means a pneumatic actuator, is kept constant over time during the tests. At the same time, the braking torque remains free to vary according to the changes in the coefficient of friction.

2) Constant torque mode: the braking torque is kept constant over time during the tests. This is done by a closed loop process that controls the applied force at each fraction of a second. A feedback from the current torque is performed by means of a torque transducer installed on the tribometer shaft. 
Figure 2.1 illustrates the scheme of the tribometer, where both the rotating and actuator systems are presented.

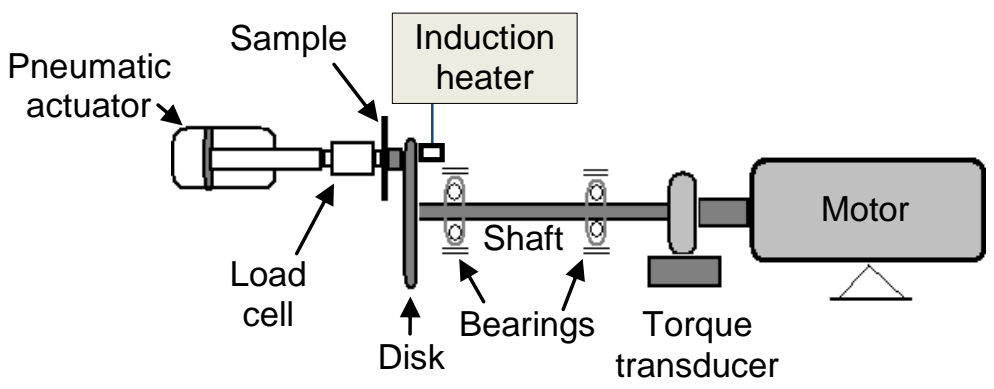

Figure 2.1 Scheme of the tribometer.

The heater and cooling systems are composed by an induction heater (Figure 2.2) and an air blower, respectively.

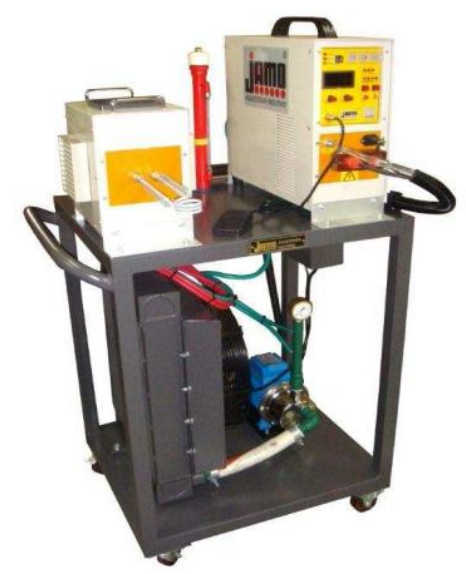

Figure 2.2 Induction heater.

\section{EXPERIMENTAL PROCEDURE}

The experiments were developed in two stages. In the sections of the first stage is assessed the influence of the intervals between braking, combined in two different initial temperatures of the disk. These stage is composed of five sections, each one composed of 10 stops, executed under operating parameters according to described in the Table 3.1.

Table 3.1 Operating parameters used in the first stage.

\begin{tabular}{|c|c|c|c|c|c|}
\hline $\begin{array}{l}\text { Braking } \\
\text { sections }\end{array}$ & $\begin{array}{l}\text { Initial temperature of } \\
\left.\text { the disk [ }{ }^{\circ} \mathrm{C}\right]\end{array}$ & $\begin{array}{l}\text { Rotating speed } \\
{[\mathrm{rpm}]}\end{array}$ & $\begin{array}{c}\text { Normal force } \\
{[\mathrm{N}]}\end{array}$ & $\begin{array}{c}\text { Intervals } \\
\text { between } \\
\text { braking [s] }\end{array}$ & $\begin{array}{l}\text { Intervals } \\
\text { between } \\
\text { sections }\end{array}$ \\
\hline 1 & 100 & 2300 & 2000 & 90 & \multirow{5}{*}{$\begin{array}{l}\text { Variable } \\
\text { irrelevant in } \\
\text { this test }\end{array}$} \\
\hline 2 & 100 & 2300 & 2000 & 600 & \\
\hline 3 & 100 & 2300 & 2000 & 90 & \\
\hline 4 & 300 & 2300 & 2000 & 18 & \\
\hline 5 & 300 & 2300 & 2000 & 600 & \\
\hline
\end{tabular}

In order to obtain intervals of $18 \mathrm{~s}$ and 90 s between braking, it was used air blowing on the disk surface for accelerating the cooling process. The interval of 600 s between braking was obtained with the help of the induction heater. 
In the second stage, the influence of the intervals between braking sections is analyzed. This stage is composed by four sections (Table 3.2) and the interval between the sections is $24 \mathrm{~h}$. Each section consists of a set of 10 stops executed under control of the initial temperature and free variation of the cooling time.

Table 3.2 Operating parameters used in the second stage.

\begin{tabular}{|c|c|c|c|c|c|}
\hline $\begin{array}{l}\text { Braking } \\
\text { sections }\end{array}$ & $\begin{array}{c}\text { Initial temperature } \\
\left.\text { of the disk [ }{ }^{\circ} \mathrm{C}\right]\end{array}$ & $\begin{array}{c}\text { Rotating speed } \\
{[\mathrm{rpm}]}\end{array}$ & $\begin{array}{c}\text { Normal force } \\
{[\mathrm{N}]}\end{array}$ & $\begin{array}{l}\text { Intervals } \\
\text { between } \\
\text { braking [s] }\end{array}$ & $\begin{array}{l}\text { Intervals } \\
\text { between } \\
\text { sections }\end{array}$ \\
\hline 6 & 100 & 2000 & 1000 & \multirow{4}{*}{$\begin{array}{l}\text { Variable } \\
\text { irrelevant in this } \\
\text { test }\end{array}$} & \multirow{4}{*}{$24 \mathrm{~h}$} \\
\hline 7 & 100 & 2000 & 1000 & & \\
\hline 8 & 100 & 2000 & 1000 & & \\
\hline 9 & 100 & 2000 & 1000 & & \\
\hline
\end{tabular}

In the sections 1 to 5 of the first stage and sections 8 and 9 of the second stage, controller gains of the normal load (a Proportional, Integral and Derivative - PID) were calibrated in order to obtain a constant and stable curve during braking. On the other hand, in the sections 6 and 7, PID gains were reduced. Table 3.3 summarizes the PID gains.

Table 3.3 PID gains in the sections.

\begin{tabular}{|c|c|}
\hline Braking sections & PID gains \\
\hline 1 to $5 ; 8$ and 9 & Calibrated PID gains \\
\hline 6 and 7 & Reduced PID gains \\
\hline
\end{tabular}

Emissivity in the disk surface is determined from the relationship between the temperature measured by thermocouple and by infrared sensor, which was adjusted with the emissivity of 1, as shows Equation 1:

$$
\varepsilon_{\mathrm{d}}=\frac{\mathrm{T}_{\mathrm{p}}^{4}}{\mathrm{~T}_{\mathrm{th}}^{4}}
$$

where $T_{p}$ is the temperature measured by infrared sensor, $T_{\text {th }}$ is the temperature measured by thermocouple e $\varepsilon_{d}$ is the emissivity of the disk. The samples used in the tests a commercial friction material, whose identification currently adopted is FL 3001539.

\section{EVALUATION OF THE INTERVAL BETWEEN BRAKING (FIRST STAGE)}

Figures 4.1 to 4.5 show the curves of coefficient of friction obtained by the first stage of the sections ( 1 to 5 ). Data are acquired during 10s. However, data analysis is done only from the first second that is the moment which the actuator force reaches $90 \%$ of the adjusted load. Similar procedure is adopted when the actuator retreats, in the instant of $7 \mathrm{~s}$.

The influence of the interval between braking on the coefficient of friction is evaluated by comparing sections which present only the same initial temperature. Hence, section 1 (Figure 4.1) is compared to section 2 (Figure 4.2), and 4 (Figure 4.4) to 5 (Figure 4.5). Section 3 serves to reaffirm the friction curve of the section 1 , since both present the same operating parameters.

By comparing Figures 4.1 and 4.2 and also Figures 4.4 and 4.5, it is observed a variation in the coefficient of friction due to different interval between braking. This is reaffirmed by section 3 , because the coefficient of friction returns to the same behavior showed in the section 1. It can be concluded that the intervals between braking $(18 \mathrm{~s}, 90 \mathrm{~s}, 600 \mathrm{~s})$ have influence in the friction coefficient behavior. By comparing Figures 4.4 and 4.5 , of the sections 4 and 5 , respectively, it is noticed a friction loss due to the temperature (fade effect) as the braking proceeds. It is because the higher initial temperature used in this case $\left(300^{\circ} \mathrm{C}\right)$. 


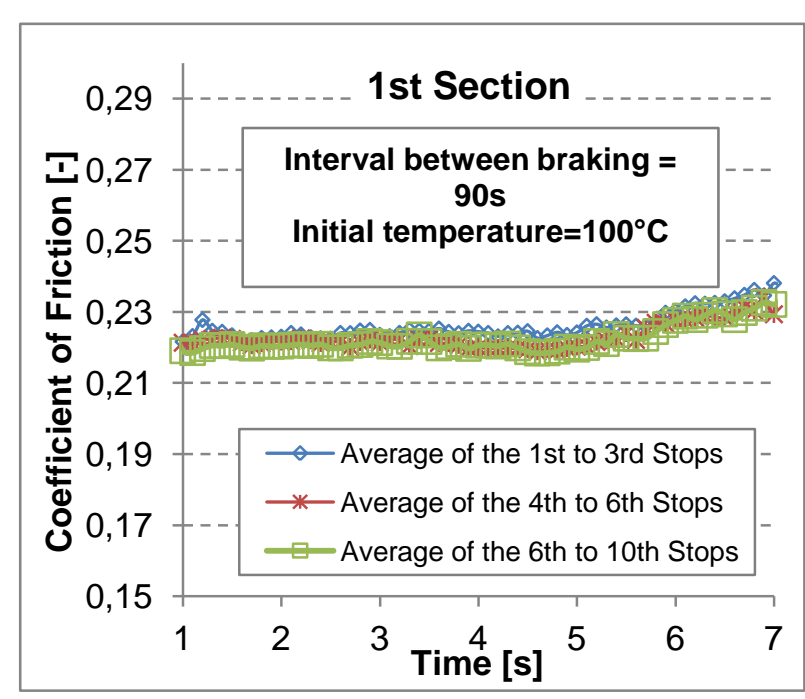

Figure 4.1 Friction curves of the section 1.

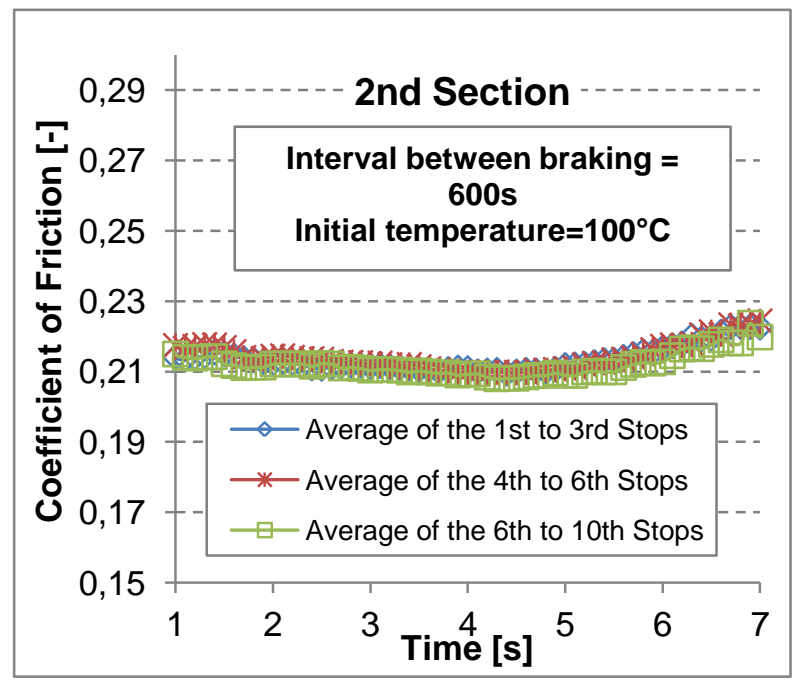

Figure 4.2 Friction curves of the section 2.

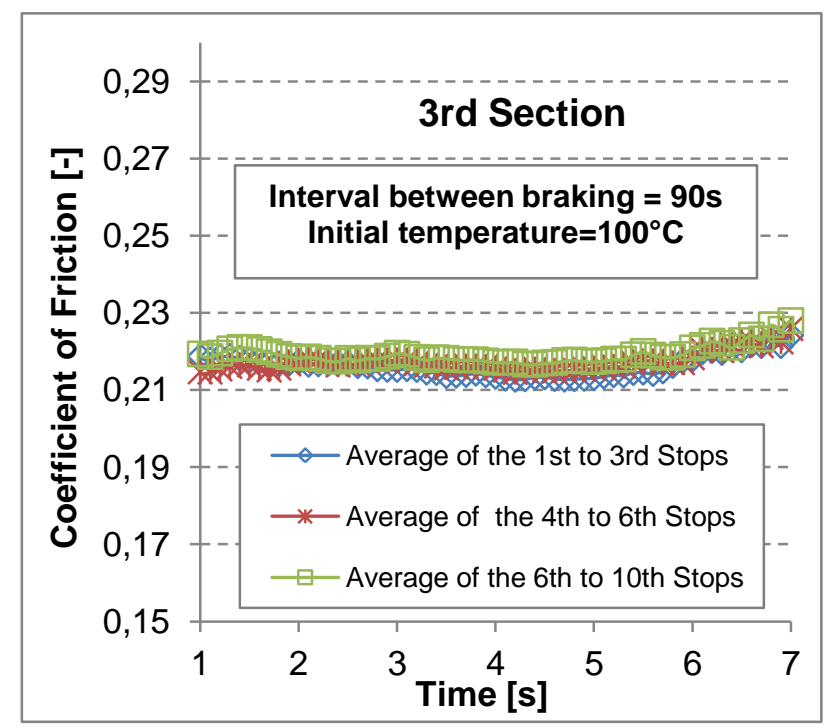

Figure 4.3 Friction curves of the section 3.

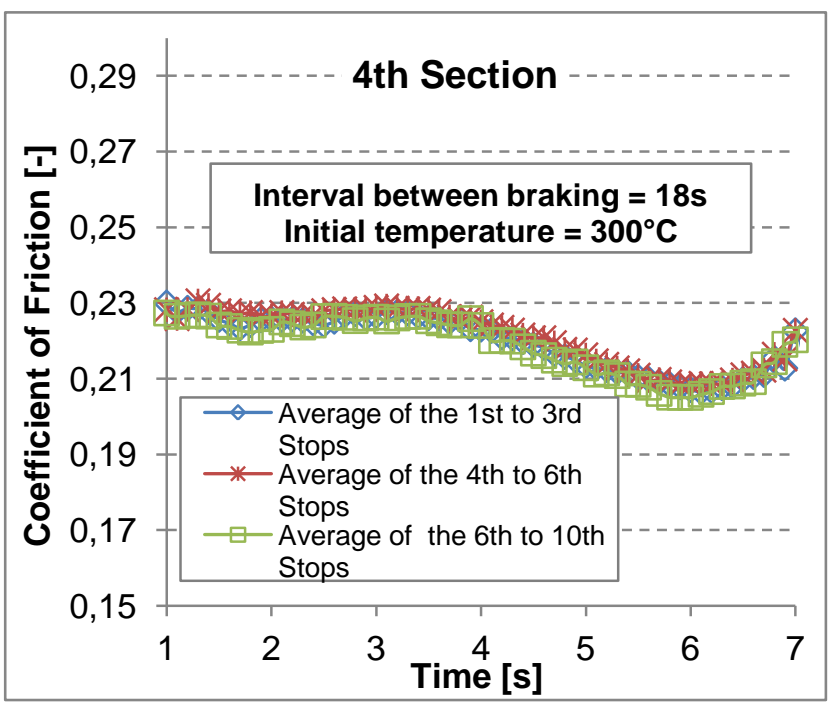

Figure 4.4 Friction curves of the section 4.

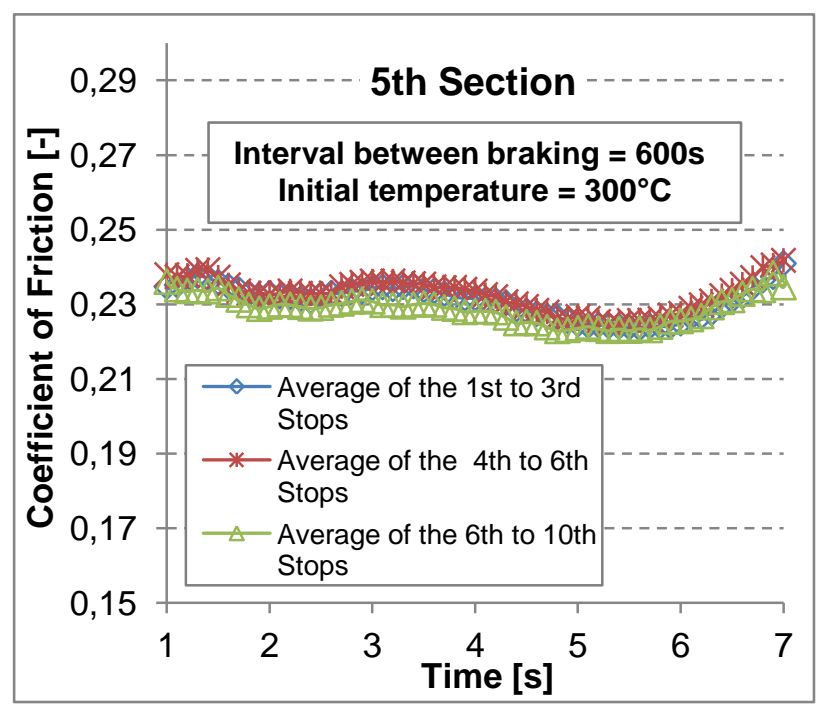

Figure 4.5 Friction curves of the section 5. 
Results of the second stage are presented in the Figures 4.6 to 4.9. Each figure has a comparison between two sections, both executed under an interval of $24 \mathrm{~h}$ among themselves and also under the same operating parameters, including PID gains.

In the graphs of the second stage, curves are shown after 3 s from data acquisition beginning because the actuator has been programmed to operate later in this case. Figures 4.7 and 4.9 present curves of normal load, where is possible to compare the actuator response related to different PID gains. Sections 6 and 7 were executed under reduced gains of the proportional (P) (Figure 4.7). Sections 8 and 9 remained with the same gains calibrated adopted in the sections 1 to 5 (Figure 4.9).

Curves of the coefficient of friction and the normal force related to the sections 6 and 7 are shown in the Figures 4.6 and 4.7 , respectively.

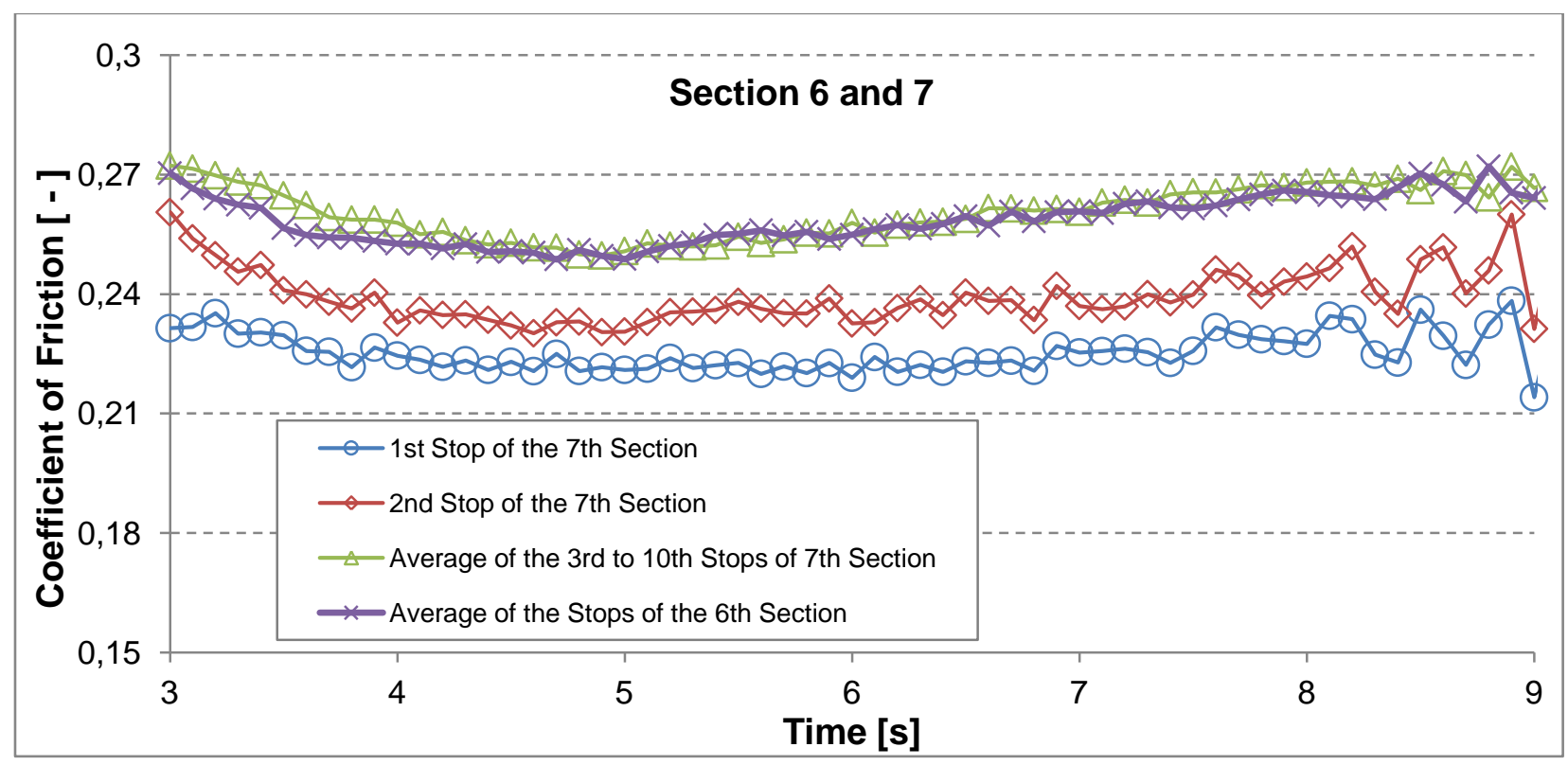

Figure 4.6 Curves of friction coefficients of the sections 6 and 7, executed under an interval of 24h between the sections (reduced PID gains).

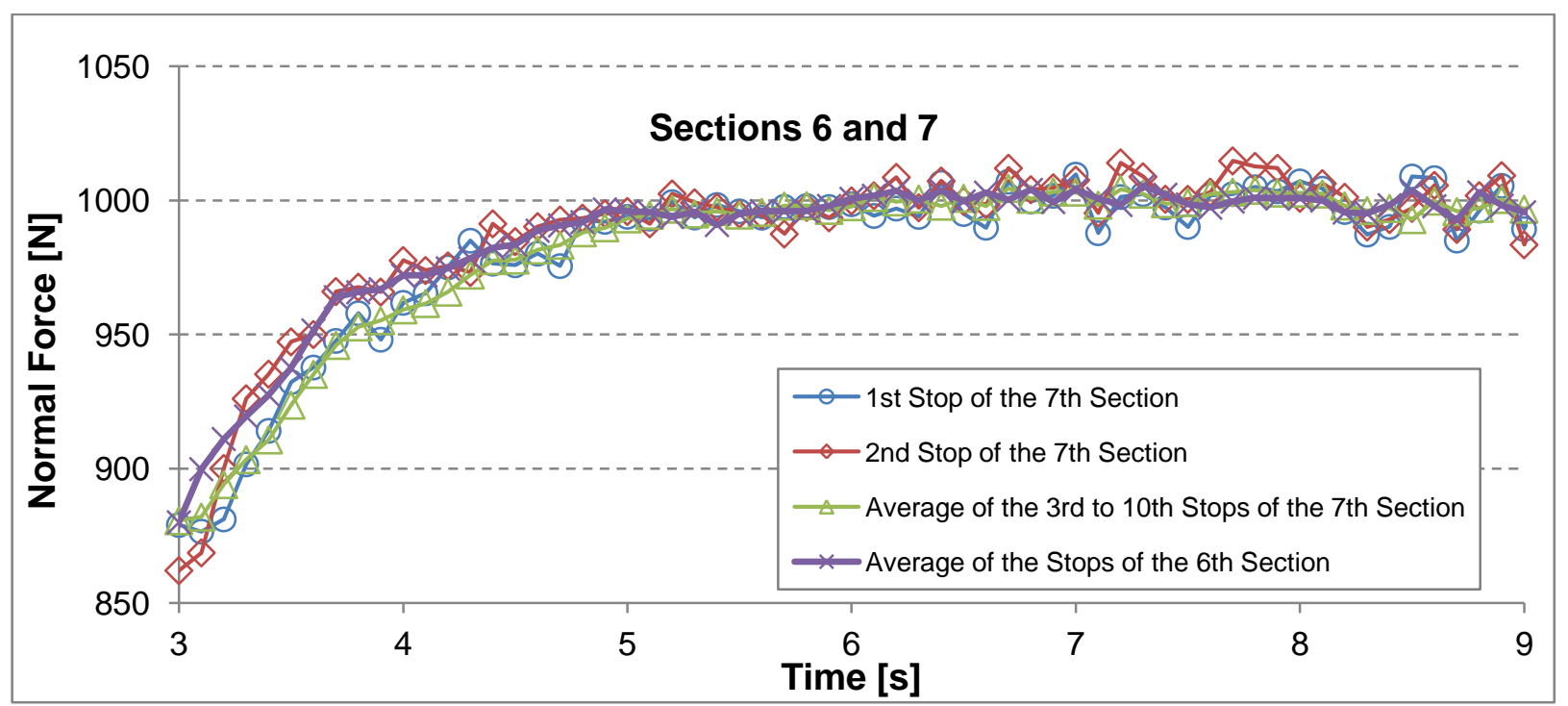

Figure 4.7 Curves of normal force of the sections 6 and 7 executed under an interval of 24h (reduced PID gains). 
By the Figure 4.6 is observed a different friction behavior in the first stop of section 7 compared to the others, since its value is lesser than the others. As the stops are performed over the section 7 , friction tends to increase in the first stops and stabilizes its level from the third stop. Figure 4.7 shows that the response of the actuator is overdamped.

Figures 4.8 and 4.9 present, respectively, coefficient of friction and normal force curves obtained from sections 8 and 9 .

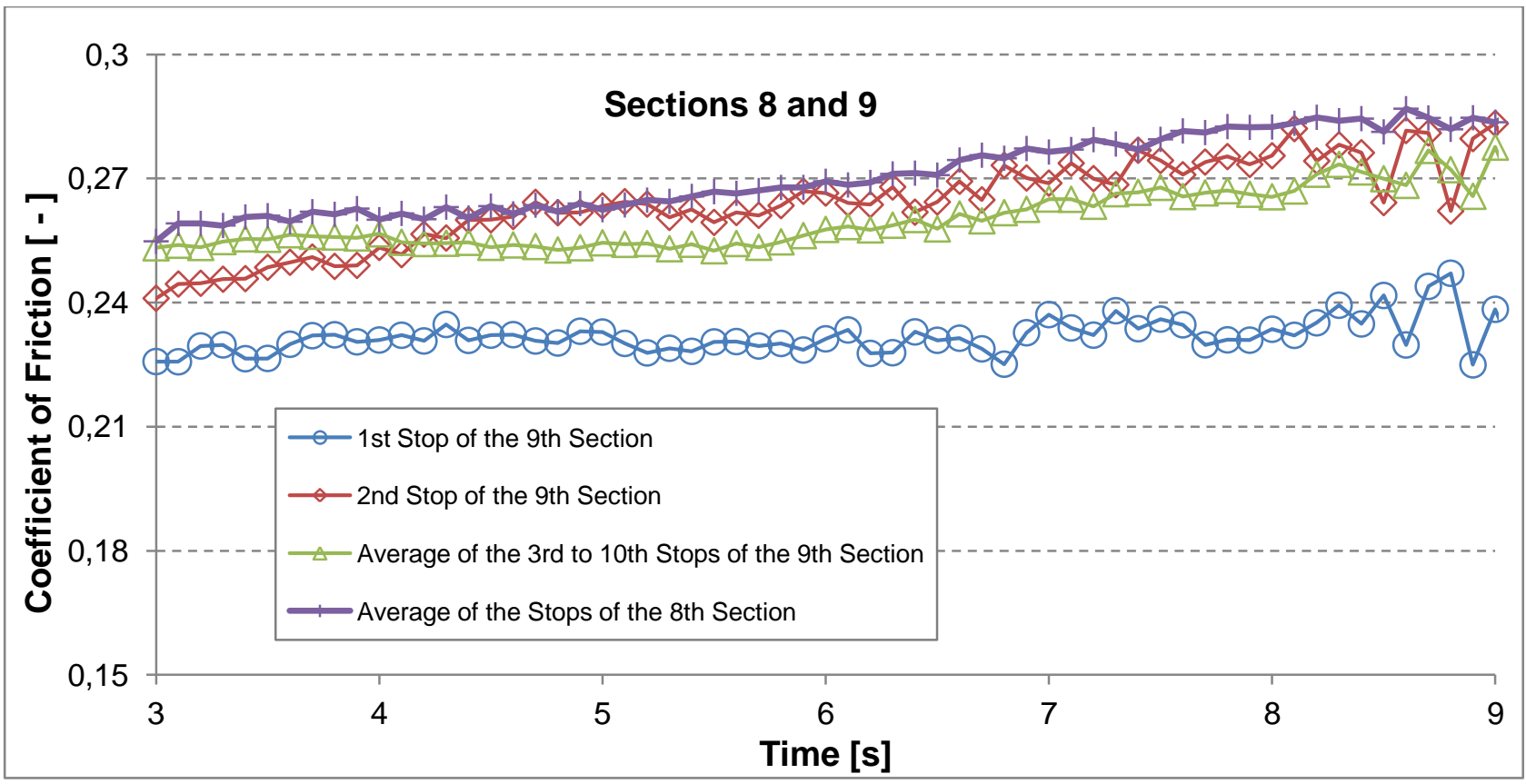

Figure 4.8 Curves of friction coefficients of the sections 8 and 9, executed under an interval of 24h between the sections (calibrated PID gains).

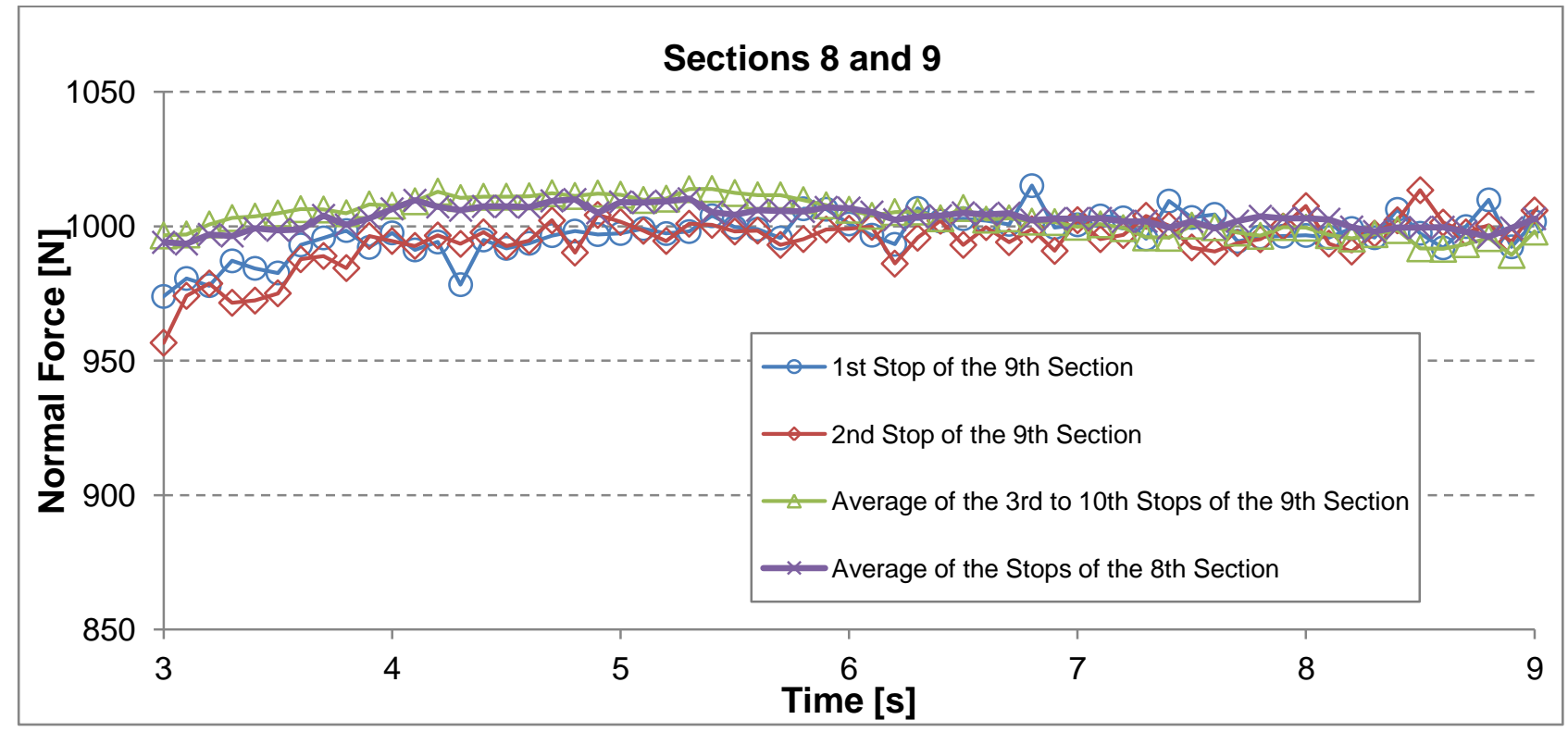

Figure 4.9 - Curves of normal force of the sections 7 and 8 executed under an interval of 24h (reduced PID gains).

Data obtained from sections $6,7,8$ and 9 indicate that the first brake shows a relatively lower coefficient of friction. This implies that there is some factor acting during the $24 \mathrm{~h}$ interval between sections which causes the friction reduction. In order to identify the responsible agent for this effect, emissivity of the disk surface is analyzed. Emissivity is a property that depends on temperature, surface quality, degree of oxidation and 
presence or absence of debris [3]. Once the experiments have been performed by using the same friction material and initial temperature $\left(100^{\circ} \mathrm{C}\right)$, differences in emissivity can be attributed to two factors, which are the oxidation degree of the surface and presence /absence of debris on the disk surface. In the current paper, analysis of the oxidation influence is relevant because it is responsible for emissivity changes [4] and an oxide layer can contribute to reduction in wear and coefficient of friction [5]. Latter effect is due to the characteristics of certain lubricants metal oxides that cause the reduction of friction coefficient [6].

Therefore, an analysis of the emissivity of the disk surface in the sections 6 to 9 is done in order to establish a relationship between oxidation and emissivity. This analysis is shown in the Figures 5.1 and 5.2. According to [7], oxidized gray cast iron has emissivity values ranging between 0.70 and 0.90 . When polished, emissivity lies between 0.30 and 0.35 .

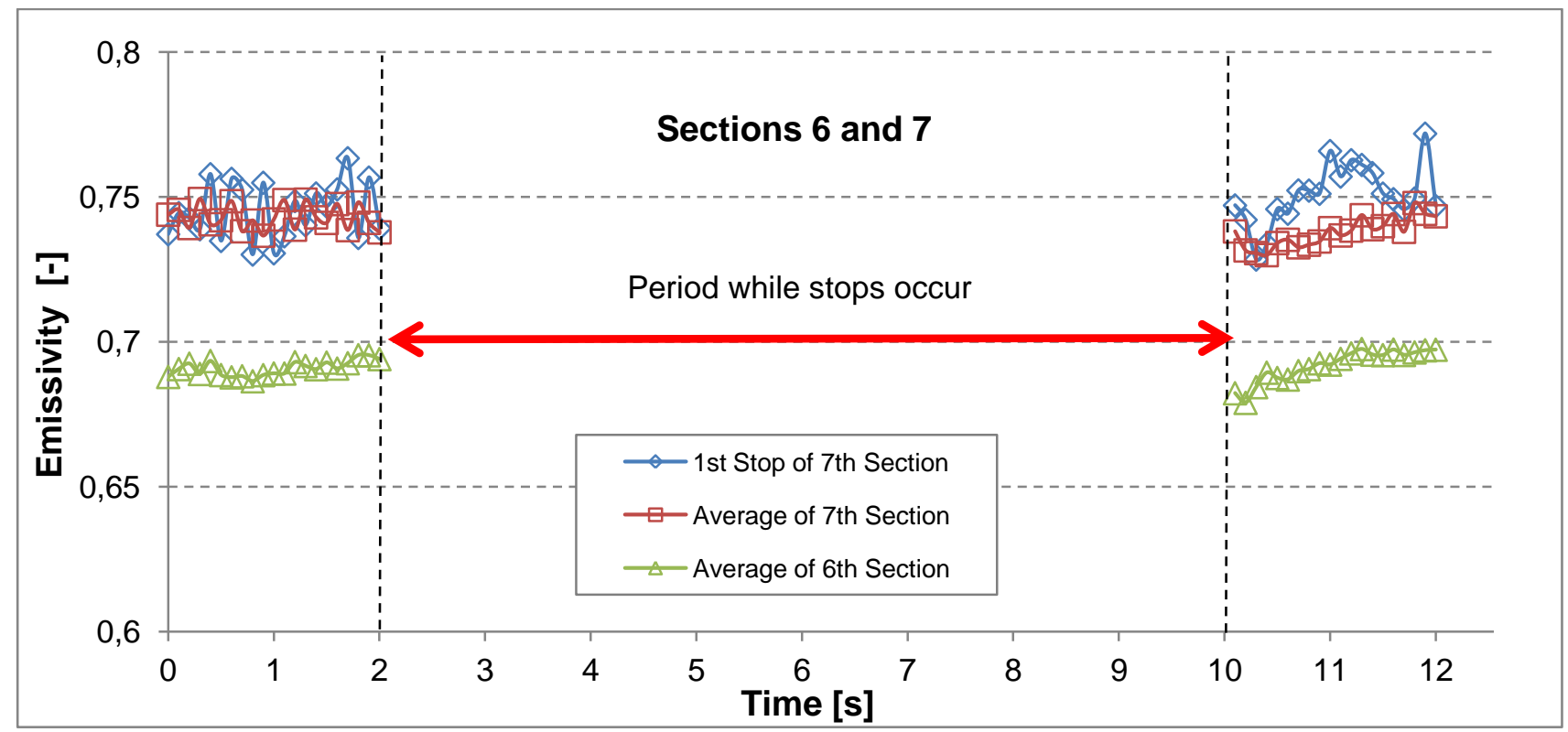

Figure 5.1 Emissivity curves of the sections 6 and 7 .

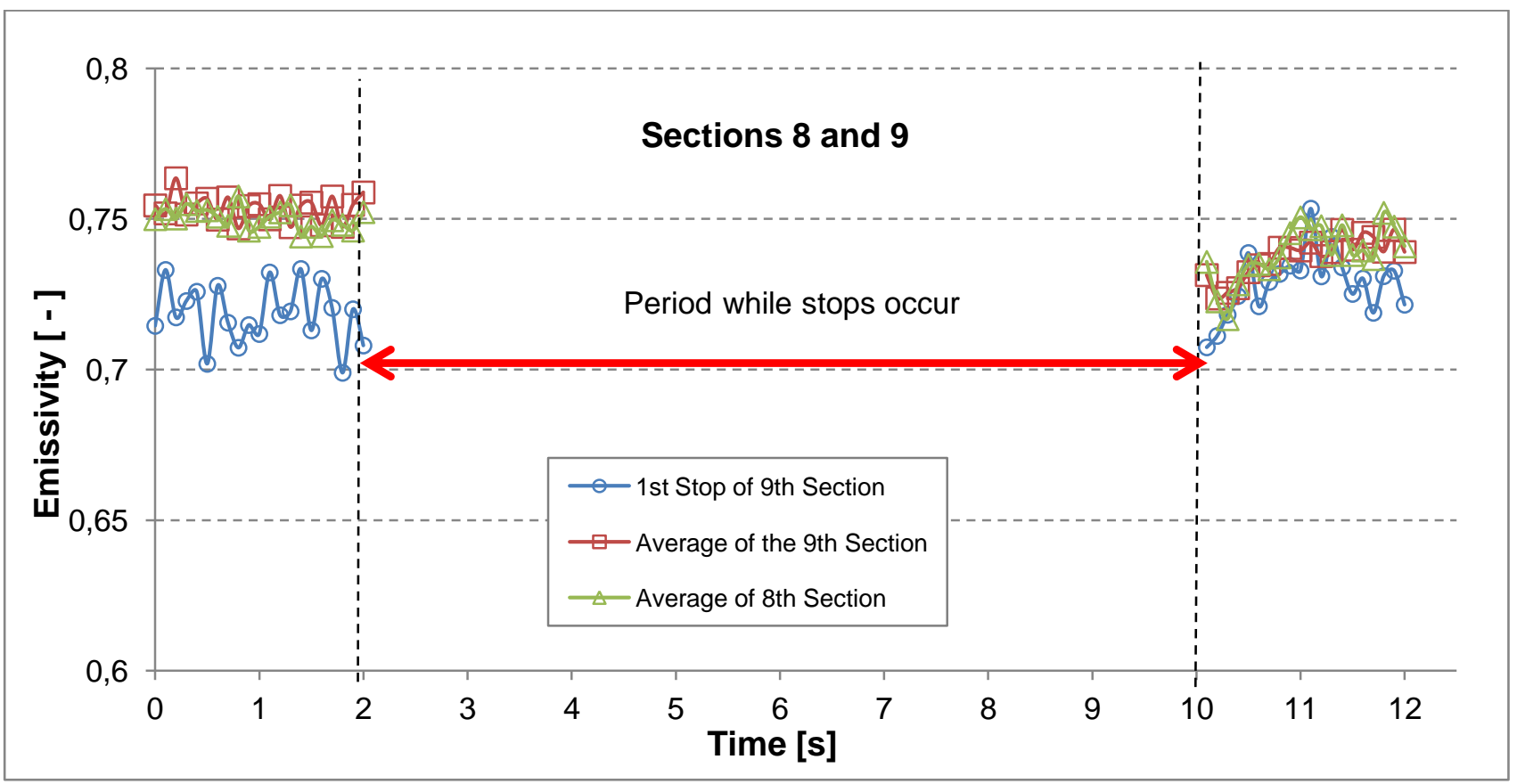

Figure 5.2 Emissivity curves of the sections 8 and 9 . 
From the Figures 5.1 and 5.2 is concluded that a relationship between emissivity and friction is difficult to identify. It is mainly due to the complex nature of both emissivity and friction.

Other experiments, this time performed on a brake dynamometer according to the procedure AK-Master standard [8], have been executed aiming to establish a relationship between coefficient of friction and emissivity. In periods when the material is subjected to high temperature (fade), torque is kept in order to guarantee a constant deceleration of the disk. In the other steps, hydraulic pressure is kept constant at 32 bar.

Figure 5.3 shows the results for a Non-Asbestos Organic (NAO) brake pad material - named OFL039 composed of a very low percentage of metal fibers. The inertia mounted into the brake dynamometer is $3.898 \mathrm{Kgm}^{2}$.

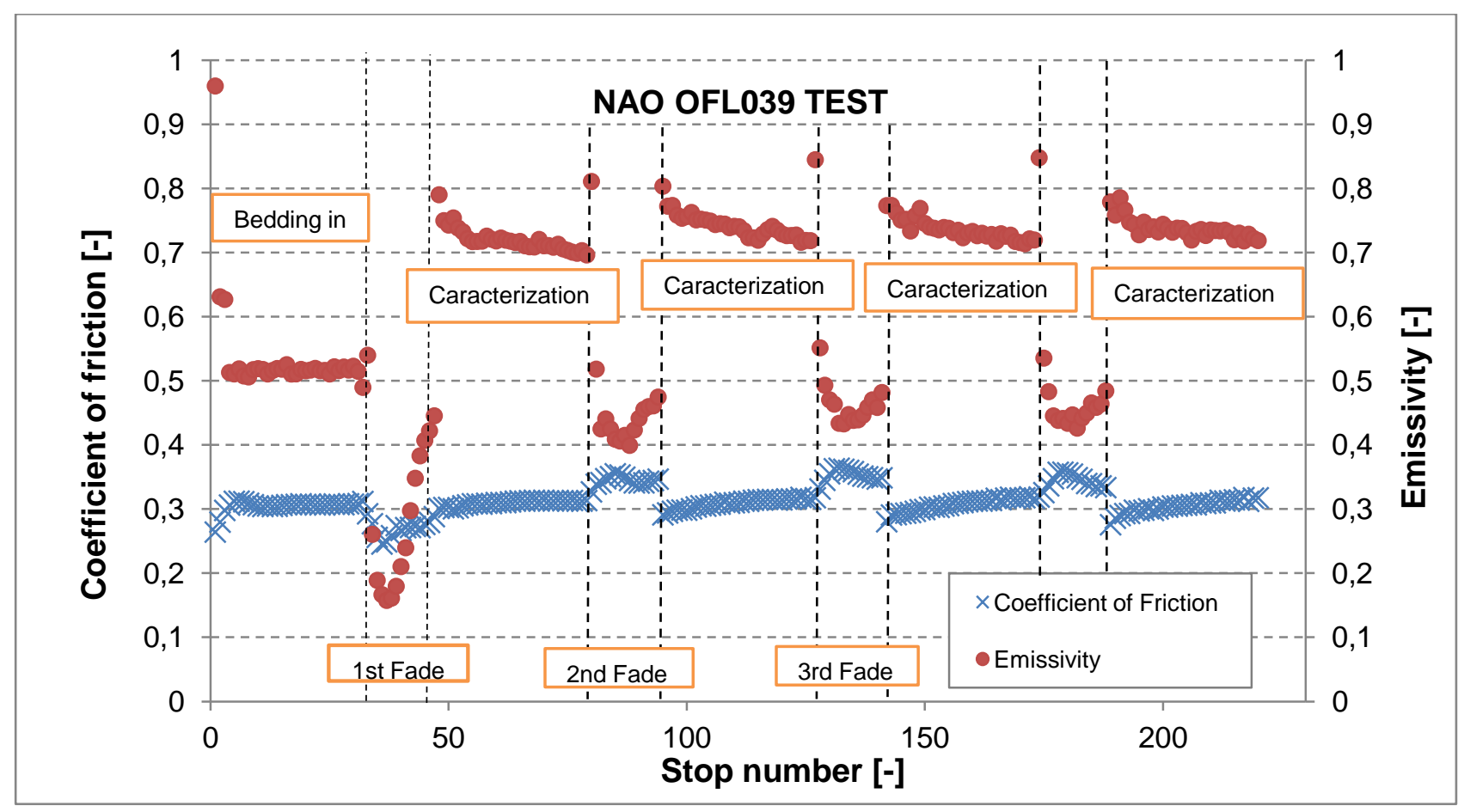

Figure 5.3 Relation between coefficient of friction and emissivity for tests performed on a brake dynamometer according to AK-Master standard procedure and by using an organic brake pad.

Figure 5.3 shows that the emissivity of the disk surface lies between 0.7 to 0.8 after the material has been submitted to the first fade. This result matches with the measurements done on the tribometer disk, whose results were shown by the Figures 5.1 and 5.2. It is worth to notice that in both machines (tribometer and dynamometer), the same type of friction material (an organic brake pad) has been used.

A similar test has been carried out on the brake dynamometer by using a Low-Metallic brake pad, which consists of a higher level of metallic compounds. Figure 5.4 shows the results obtained in this test. Curves presented by the Figure 5.4 reinforce the assertion that a relationship between emissivity and friction seems not clear to identify, since both emissivity and friction vary according to the step. Besides, by comparing results obtained from organic and low metallic brake pads is concluded that emissivity property also depends on the nature of the friction material used in the tests. Consequently, it is not possible to conclude if the differences in coefficient of friction observed during the first stop of the sections 7 and 9 (Figures 4.6 and 4.8, respectively) occur due to the level oxidation on the disk surface. 


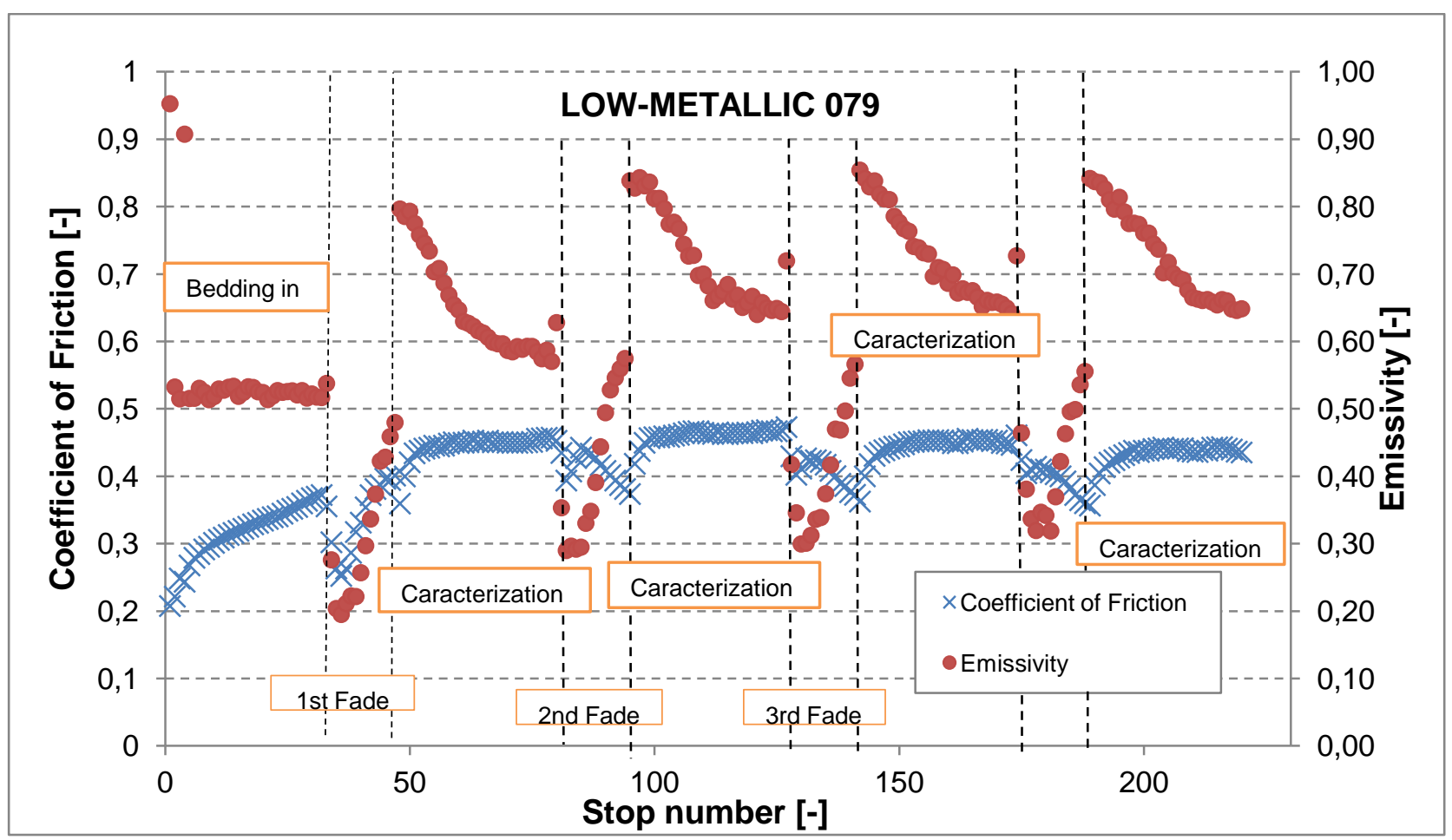

Figure 5.4 Relation between coefficient of friction and emissivity for tests performed on a brake dynamometer according to AK-Master standard procedure and by using a Low-Metallic brake pad.

\section{CONCLUSIONS}

Results from the current paper show that the cooling time between braking is a variable that plays an important role on coefficient of friction. However, it was not possible to identify the responsible factor for this effect. The level of oxidation in the disk surface cannot be evaluated from the emissivity measurements since other factors such as debris, system vibration or chemical changes in the disk also seem to affect this property, making the analysis complex.

According to the tribometer and brake dynamometer results, the relationship between friction and emissivity is complex. Results show that emissivity property depends on the nature of the friction material used in the friction process.

\section{REFERENCES}

[1] R. F. Neuman, J. H. McNinch, Performance Characterization of Dry Friction Materials, IMech E, pp 233-238, 1983.

[2] F. Van Velde, P. Baets, Comparison of Two Stick-Slip Tester and Recommendations for Repeatable And Significant Stick-Slip Testing, Tribotest Journal 3-4, 1997.

[3] J. Thevenet, M. Siroux, B. Desmet, Measurements of Brake Disc Surface Temperature and Emissivity by Two-Color Pyrometry, Applied Thermal Engineering 30, pg 753-759, 2010.

[4] V. P. Nicolau, S. Güths, Medição de Emissividade e de Temperatura sem Contato - Experimento Didático, Congresso Brasileiro de Engenharia Mecânica, 1997.

[5] G. W. Stachowiak, A. W. , Engineering Tribology, $3^{\text {rd }}$ edition, pg 590, 2005.

[6] P. J. Blau, J. C. McLaughlin, Effects of Water Films and Sliding Speed on the Frictional Behavior of Truck Disc Brake Materials, Tribology International 36, pg 709-715, 2003

[7] Raytek, Introduction Manual-Infrared Sensor, $4^{\text {th }}$ edition.

[8] AK-Master Standard, In Brake German Procedures, Germany, 1998. 